\title{
ANALISIS EFISIENSI PENGGUNAAN ENERGI LISTRIK DI GEDUNG MADRASAH IBTIDAIYAH MUHAMMADIYAH I PEKANBARU
}

\author{
Elvira Zondra ${ }^{1}$, Atmam $^{2}$, Hazra Yuvendius ${ }^{3}$ \\ 1,2,3 Program Studi Teknik Elektro, Fakultas Teknik, Universitas Lancang Kuning \\ Jl. Yos Sudarso km. 8 Rumbai, Pekanbaru, Telp. (0761) 52324 \\ Email: elviraz@unilak.ac.id, atmam@unilak.ac.id,hazra_yuvendius@unilak.ac.id
}

\begin{abstract}
ABSTRAK
Energi memiliki peran penting dalam kehidupan manusia dan pembangunan saat ini. Seiring dengan meningkatnya konsumsi energi oleh masyarakat, maka Perusahaan Listrik Negara harus meningkatkan pasokan energi listrik agar jumlah daya listrik yang tersedia memenuhi permintaan energi listrik oleh konsumen. Pelaksanaan konservasi energi di Indonesia diatur oleh Peraturan Pemerintah No. 70 tahun 2009. Konservasi energi adalah upaya sistematis, terencana, dan terpadu guna melestarikan sumber daya energi dalam negeri serta meningkatkan efisiensi pemanfaatannya. Penelitian ini mendapatkan tingkat efisiensi penggunaan energi listrik dengan menentukan nilai intensitas konsumsi Energi (IKE) sesuai dengan Peraturan Menteri ESDM No.13 tahun 2012 tentang Penghematan Pemakaian Tenaga Listrik dan SNI 03-6196-2000 tentang Prosedur Audit Energi Pada Bangunan Gedung Oleh Badan Standarnisasi Nasional. Tingkat efisiensi yang didapatkan adalah pada nilai IKE antara 0,07 sampai dengan 1,17. Nilai IKE ini adalah pada kategori sangat efisien.
\end{abstract}

Kata Kunci : Energi, konservasi energi, intensitas konsumsi energi

\begin{abstract}
Energy has an important role in human life and development today. Along with the increase in energy consumption by the public, the National Electricity Company must increase the supply of electricity so that the amount of available electricity meets the demand for electricity by consumers. The implementation of energy conservation in Indonesia is regulated by Government Regulation no. 70 of 2009. Energy conservation is a systematic, planned and integrated effort to preserve domestic energy resources and improve the efficiency of their use. This study obtained the efficiency of electricity use by determining the value of energy consumption intensity (IKE) in accordance with ESDM Minister Regulation No. 13 of 2012 concerning the Saving of Electric Power Use and SNI 03-6196-2000 on Energy Audit Procedures in Building Buildings by the National Standards Agency. The level of efficiency obtained is in the IKE value between 0.07 to 1.17. This IKE value is in the very efficient category.
\end{abstract}

Keywords: Energy, energy conservation, energy consumption intensity

\section{PENDAHULUAN}

Energi memiliki peran penting dalam kehidupan manusia dan pembangunan saat ini. Seiring dengan meningkatnya konsumsi energi oleh masyarakat, maka Perusahaan Listrik Negara harus meningkatkan pasokan energi listrik agar jumlah daya listrik yang tersedia memenuhi permintaan energi listrik oleh konsumen.

Besarnya biaya investasi dalam pembangunan pembangkit listrik baru merupakan permasalahan yang timbul karenanya. Salah satu usaha yang dilakukan untuk mengatasi masalah tersebut adalah dengan melakukan penghematan, mengefisienkan pemakaian energi listrik tersebut. Mengefisienkan pemakaian energi listrik ini dikenal dengan istilah konservasi energi. Konservasi energi pada bangunan gedung di Indonesia dimulai sejak tahun 1985 dengan diperkenalkannya program DOE (Department Of Energy, USA) oleh Departemen Pekerjaan Umum (SNI 03-6196-2000).

Pelaksanaan konservasi energi di Indonesia diatur oleh Peraturan Pemerintah no. 70 tahun 2009. Konservasi energi adalah upaya sistematis, terencana, dan terpadu guna melestarikan sumber daya energi 
dalam negeri serta meningkatkan efisiensi pemanfaatannya.

Madrasah Ibtidaiyah Muhammadiyah I Pekanbaru terletak di kecamatan Rumbai Pekanbaru. Sekolah ini merupakan Madrasah Ibtidaiyah yang dikelola oleh organisasi sosial kemasyarakatan Muhammadiyah Pekanbaru. Madrasah Ibtidaiyah Muhammadiyah I Pekanbaru memiliki infrastruktur berupa ruangan untuk kegiatan belajar mengajar dan ruangan pendukung yang terdiri dari 12 ruangan kelas, 1 ruang kepala sekolah, 2 ruang guru, 1 ruang tata usaha, dan 4 buah kamar mandi. Untuk kegiatan belajar mengajar serta pendukungnya dibutuhkan peralatan-peralatan yang membutuhkan energi listrik seperti lampu untuk penerangan, kipas angin dan Air Condesioner untuk pendingin, pompa air untuk keperluan kamar mandi dan berwudhu, komputer serta printer untuk belajar mengajar dan keperluan administrasi.

Dengan meningkatnya jumlah siswa dari tahun ke tahun maka dilakukan pembangunan kelas seara bertahap dan baru selesai sebanyak 2 kelas yang juga akan membutuhkan energi listrik. Pembangunan kelas baru ini dilakukan atas pertimbangan persentase peningkatan jumlah siswa yang cukup banyak yaitu kurang lebih $5 \%$ setiap tahunnya. Penggunaan energi listrik berhubungan dengan biaya yang harus dikeluarkan sekolah untuk penggunaan energi listrik tersebut.

Guna konservasi energi dan pertimbangan diatas maka dilakukan penelitian ini dengan dasar data beban existing dan penambahan jumlah siswa dan ruangan. Kemajuan sekolah saat ini dengan meningkatnya jumlah siswa dan ditambahnya ruangan, berpengaruh terhadap jumlah kebutuhan energi setiap ruangan dilingkungan Madrasah Ibtidaiyah Muhammadiyah I Pekanbaru dan biaya yang dikeluarkan. Oleh karena itu maka analisis efisiensi penggunaan energi listrik dibutuhkan, sehingga pengendalian penggunaan energi bisa dilaksanakan agar konservasi energi tercapai.

\section{Beban Listrik}

Pembangkit listrik yang ada harus menopang beban listrik pada jaringan listrik AC. Ada tiga jenis beban yang di suplai oleh pembangkait rersebut. Ketiga jenis beban tersebut adalah beban resistif, beban induktif, dan beban kapasitif. Ketiga jenis beban ini memiliki karakteristik yang berbeda antara satu sama lainnya.

Beban resistif terdapat pada alat-alat listrik yang bersifat murni tahanan (resistor), diantaranya pada elemen pemanas dan lampu pijar. Beban resistif memiliki sifat pasif, dimana resistor mengambil energy listrik dari sumber dan tidak dapat mengembalikannya lagi [1]. Resistor tidak mampu memproduksi energi listrik, dan hanya menjadi konsumen energi listrik. Daya yang diserap secara fisika akan muncul sebagai panas dan/ atau cahaya dan selalu berharga positif [2].

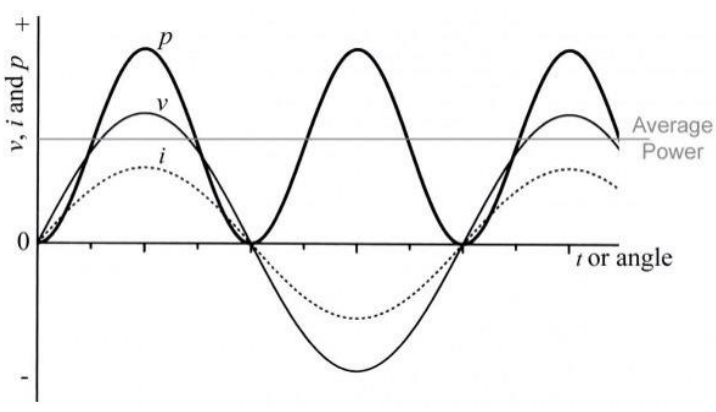

Gambar 1. Gelombang Sinusoidal Beban Resistif

Gelombang arus dan tegangan listrik yang melewati resistor akan selalu bersamaan, karena pada beban resistif ini arus dan tegangan sephasa.

Beban induktif muncul oleh lilitan kumparan yang terdapat pada alat-alat listrik seperti motor, generator, transformator, dan relay. Induktor merupakan sebuah elemen rangkaian yang menyimpan energi selama satu periode waktu dan mengembalikannya selama satu periode waktu lain Tegangan dalam sebuah induktansi merupakan laju perubahan arus terhadap waktu yang menghasilkan medan magnet. Kumparan dibutuhkan oleh alat-alat listrik untuk menciptakan medan magnet sebagai komponen kerjanya. Pembangkitan medan magnet pada kumparan inilah yang menjadi beban induktif pada rangkaian arus listrik sinusoidal.

Induktor adalah komponen listrik yang menentang apapun perubahan arus [3]. Perilaku induktor didasarkan pada fenomena terkait dengan medan magnet. Sumber dari medan magnet muatan bergerak, atau arus. Arus listrik yang sinusoidal memiliki nilai arus yang naik turun. Perubahan arus listrik yang naik turun inilah yang dihalangi oleh komponen kumparan di dalam sebuah rangkaian listrik sinusoidal sehingga mengakibatkan arus listrik menjadi tertinggal beberapa derajat dari tegangan listrik. Pada induktif murni gelombang arus listrik akan tertinggal sejauh $90^{\circ}$ oleh gelombang tegangan. Beban induktif dikenal dengan istilah beban lagging. Energi yang diterima oleh induktor disimpan didalam medan magnet.

Kurva sinusoidal arus dan tegangan listrik dari sebuah induktor seperti pada gambar 2 .

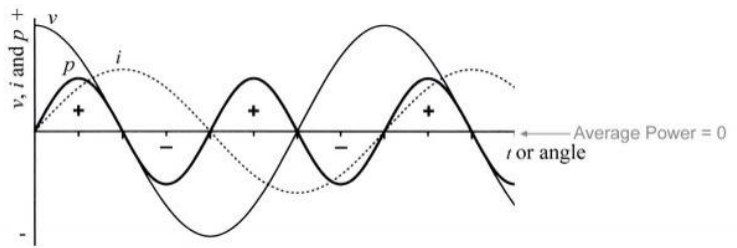

Gambar 2. Gelombang Sinusoidal Beban Induktif 
Kapasitor adalah komponen listrik yang terdiri dari dua konduktor yang dipisahkan oleh isolator atau bahan dielektrik. Kapasitor adalah satu-satunya perangkat selain batery yang dapat menyimpan muatan listrik. Perilaku kapasitor didasarkan pada fenomena terkait dengan medan listrik. Sumber medan listrik adalah pemisahan muatan, atau tegangan. Jika tegangan berubah terhadap waktu, medan listrik juga akan berubah terhadap waktu [3]. Beban kapasitif merupakan kebalikan dari beban induktif. Beban kapasitif bersifat menghalangi terjadinya perubahan nilai tegangan listrik. Sifat ini menunjukkan bahwa kapasitor bersifat seakan-akan menyimpan tegangan listrik sesaat.

Apabila kapasitor mendapatkan supply tegangan sinusoida, maka kapasitor akan menyimpan dan melepaskan tegangan listrik sesuai dengan perubahan tegangan masuk. Hal inilah yang mengakibatkanpada beban kapasitif murni, gelombang arus sinusoida akan mendahului (leading) tegangannya sejauh $90^{\circ}$.

Kurva sinusoidal arus dan tegangan listrik dari sebuah kapasitor seperti pada gambar 3.

\section{Daya Listrik Dan Faktor Daya}

Daya listrik merupakan jumlah energi listrik yang digunakan tiap detik. Ada 3 jenis daya listrik yaitu
a. Daya semu
b. Daya nyata
c. Daya reaktif

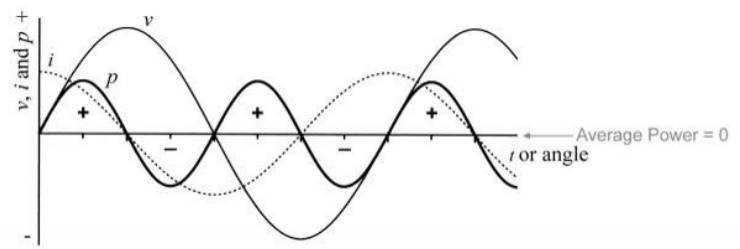

Gambar 3. Gelombang Sinusoidal Beban Kapasitif

Daya semu (daya kompleks) merupakan penjumlahan dari daya nyata dengan daya reaktif.

$$
S=P+j Q
$$

Satuan yang digunakan untuk daya semu adalah Volt Amper, Satuan yang digunakan untuk daya nyata adalah Watt dan satuan untuk daya reaktif adalah VAr (Volt Ampere Reactive), dimana

$$
S=\sqrt{P^{2}+Q^{2}}
$$

dengan:

$$
\begin{aligned}
& \text { S = Daya Semu (VA) } \\
& P=\text { Daya Aktif (Watt) } \\
& Q=\text { Daya Reaktif (VAr) }
\end{aligned}
$$

Besarnya daya semu, daya aktif dan daya reaktif dipengaruhi oleh jenis beban resistif, induktif dan kapasitif. Rasio antara daya rata-rata, terhadap daya semu disebut sebagai faktor daya (power factor), dilambangkan oleh PF. Sewaktu menyebutkan factor daya, adalah lazim memasukkan informasi mengenai tanda $\theta$ dengan menyatakan faktor daya tertinggal (arus tertinggal dari tegangan) atau faktor daya mendahului (arus mendahului tegangan) [1].

Semakin besar beban induktif maka akan menyebabkan besar pula daya reaktif dan memperkecil faktor daya. Faktor daya yang bagus adalah faktor daya yang mendekati nilai 1. Faktor daya rendah dapat diperbaiki dengan cara pemasangan kompensasi daya reaktif pada sisi beban. Pada PUIL 2011 direkomendasikan nilai faktor daya terendah adalah 0,8. Pada jaringan pasif dengan impedansi Z didapatkan [4].

$$
P F=\cos \phi=\frac{R}{Z}
$$

Faktor daya dapat juga dinyatakan dengan perbandingan antara daya aktif dengan daya nyata.

$$
\begin{aligned}
P F & =\frac{\text { daya rata }- \text { rata }}{\text { daya semu }}=\frac{P}{S} \\
& =\frac{P}{\sqrt{P^{2}+Q^{2}}}
\end{aligned}
$$

Kompensasi Daya reaktif dapat ditentukan dengan menetapkan nilai faktor daya target yang diinginkan dari perbaikan.

$$
\begin{aligned}
\tan \theta_{2} & =\frac{Q_{2}}{P} \\
& =\frac{Q_{1}-Q_{C}}{P}
\end{aligned}
$$

$P \tan \theta_{2}=Q_{1}-Q_{C}$

$$
Q_{C}=Q_{1}-P \tan \theta_{2}
$$

$$
=\left(V \times I \times \sin \theta_{1}\right)-\left(V \times I \times \cos \theta_{1}\right) \tan \theta_{2}
$$

$$
\begin{aligned}
& =V \times I \times \cos \theta_{1} \times \frac{\sin \theta_{1}}{\cos \theta_{1}}-\left(V \times I \times \cos \theta_{1}\right) \tan \theta_{2} \\
& =V \times I \times \cos \theta_{1}\left(\tan \theta_{1}-\tan \theta_{2}\right) \\
& =V \times I \times \cos \theta_{1}\left(\tan \left(\cos ^{-1} p f_{1}-\tan \left(\cos ^{-1} p f_{2}\right)\right)\right.
\end{aligned}
$$

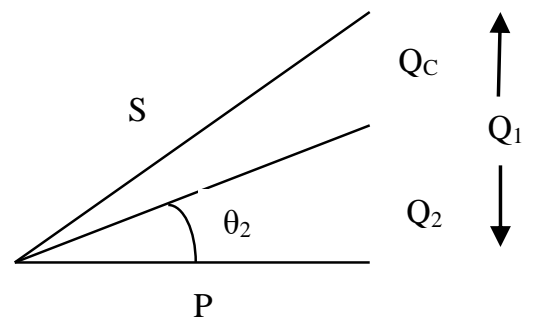

Gambar 4. Perbaikan Faktor Daya 


\section{Intensitas Konsumsi Energi}

Intensitas Konsumsi Energi (Energy Use Intensity) adalah suatu nilai atau besaran yang menjadi indikator ukuran tingkat pemanfaatan energi. Berdasarkan Peraturan Menteri ESDM no.13 tahun 2012, standar Intensitas Konsumsi Energi (IKE) dengan kriteria Penggunaan Energi di Gedung Perkantoran (kWh/m2/bulan) tergantung kepada jumlah energi yang digunakan dan luas gedung. Untuk bangunan yang menggunakan AC dan tidak, memiliki cara penilaian tingkat keefisienan yang berbeda seperti terlihat di tabel 1 dan tabel 2 .

Tabel 1. Nilai IKE di gedung perkantoran ber AC

\begin{tabular}{cc}
\hline Kriteria & Konsumsi Energi Spesifik $\left(\mathrm{kWH} / \mathrm{m}^{2} / \mathrm{bulan}\right)$ \\
\hline Sangat Efisien & Lebih kecil dari 8,5 \\
Efisien & 8,5 sampai dengan lebih kecil dari 14 \\
Cukup Efisien & 14 sampai dengan lebih kecil dari 18,5 \\
Boros & Lebih besar sama dengan 18,5 \\
\hline
\end{tabular}

Tabel 2. Nilai IKE di gedung perkantoran tanpa AC

\begin{tabular}{cc}
\hline Kriteria & Konsumsi Energi Spesifik $\left(\mathrm{kWH} / \mathrm{m}^{2} / \mathrm{bulan}\right)$ \\
\hline Sangat Efisien & Lebih kecil dari 3,4 \\
Efisien & 3,4 sampai dengan lebih kecil dari 5,6 \\
Cukup Efisien & 5,6 sampai dengan lebih kecil dari 7,4 \\
Boros & Lebih besar sama dengan 7,4 \\
\hline
\end{tabular}

Jika persentase perbandingan luas lantai menggunakan AC terhadap luas total gedung kurang dari $10 \%$ maka gedung tersebut termasuk gedung yang tidak menggunakan AC. Jika persentase perbandingan luas lantai menggunakan AC terhadap luas total gedung lebih dari $90 \%$ maka gedung tersebut termasuk gedung yang menggunakan AC dan konsumsi energi perluas lantai dapat ditentukan dengan persamaan :

$$
I K E=\frac{\text { Total konsumsiEnergi }}{\text { Luas Lantai total }}
$$

Jika persentase perbandingan luas lantai menggunakan AC terhadap luas total gedung lebih dari $10 \%$ dan kurang dari $90 \%$ maka gedung tersebut termasuk gedung yang menggunakan AC tidak menggunakan AC.

$$
I K E=\frac{\text { Total konsumsi Energi }- \text { konsumsi energi AC }}{\text { Luas Lanta total }}
$$

\section{Penggunaan Energi Listrik}

Peruntukan golongan tarif listrik untuk sekolah adalah golongan tarif listrik sosial. Berdasarkan Peraturan Menteri ESDM no. 31 tahun 2014, biaya pemakaian energi listrik untuk kelompok tarif dasar listrik keperluan sosial menurut golongan tarif dan batas daya yang akan dibayarkan kepada PT. PLN terdapat pada Tabel 3.

Tabel 3. Kelompok Tarif Dasar Listrik Untuk Keperluan Sosial

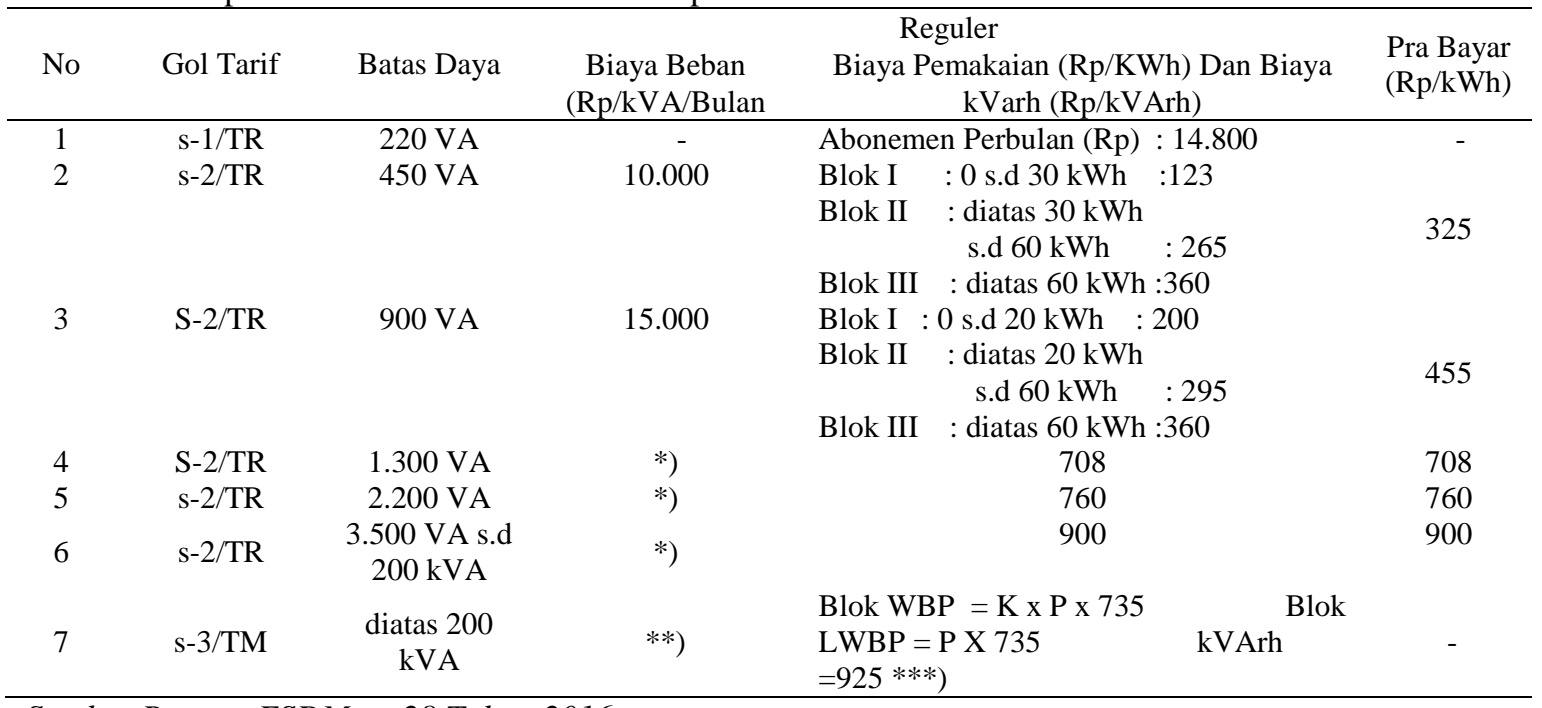

Sumber Permen ESDM no 28 Tahun 2016 


\section{Tingkat pencahayaan}

Pada tingkat pencahayaan terdapat lima istilah standar dalam pencahayaan beserta satuannya antara lain:

a. Arus cahaya (luminous flux) adalah banyak cahaya yang dipancarkan ke segala arah oleh sebuah sumber cahaya per satuan waktu (biasanya per detik), diukur dengan Lumen.

b. Intensitas cahaya (luminous intensity) adalah kuat cahaya yang dikeluarkan oleh sebuah sumber cahaya ke arah tertentu, diukur dengan Candela.

c. Iluminan (illuminance) adalah banyak arus cahaya yang datang pada satu unit bidang, diukur dengan Lux atau Lumen $/ \mathrm{m}^{2}$, sedangkan prosesnya disebut iluminasi (illumination) yaitu datangnya cahaya ke suatu objek.

d. Luminan (luminance) adalah intensitas cahaya yang dipancarkan, dipantulkan dan diteruskan oleh satu unit bidang yang diterangi, diukur dengan Candela $/ \mathrm{m}^{2}$, sedangkan prosesnya disebut luminasi (lumination) yaitu perginya cahaya dari suatu objek.

e. Efikasi adalah Hasil bagi antara fluks luminus (lumen) dengan daya listrik masukan suatu sumber cahaya yang dinyatakan dalam satuan lumen per Watt (SNI 03-6197-2000).

Berdasarkan standar nasional Indonesia 036197-tahun 2000, tingkat pencahayaan minimal yang direkomendasikan tidak boleh kurang dari tingkat pencahayaan yang telah diatur yaitu untuk ruang kelas 250 lux, ruang kerja 350 lux dan ruang komputer 350 lux serta kamar mandi 250 lux. Sedangkan daya listrik maksimum per meter persegi tidak boleh melebihi nilai $15 \mathrm{Watt} / \mathrm{m}^{2}$ untuk ruang kerja dan ruang kelas.

\section{METODE PENELITIAN}

Metode dan Tahapan pelaksanaan penelitian ini sebagai berikut :

\subsection{Metode pengumpulan data}

Metode yang digunakan pada proses pengumpulan data yaitu

a. Pengumpulan data sekunder yaitu berupa data penggunaan energi listrik dan biaya rekening pembayarannya.

b. Pengumpulan data primer yaitu dengan melakukan pengukuran dan pemeriksaan pada masing-masing ruangan. Data atau variable yang akan diukur dan diperiksa adalah data konsumsi daya pada peralatan pendingin ruangan, peralatan penerangan dan peralatan listrik lain seperti komputer, printer, pemanas air, pompa air, viewer dan lain-lain.

\subsection{Metode Pengolahan data}

Metoda pengolahan data dilakukan setelah pengumpulan data berupa data penggunaan energi listrik dan biaya rekening pembayarannya serta data dari pengukuran.

1. Pengumpulan data penggunaan energi listrik

2. Mengukur dan menghitung penggunaan energi dengan beban penerangan pada
a. Ruang Kepala Sekolah
b. Ruang Guru
c. Ruang Kelas
d. Ruang kantor tata usaha
e. Kamar mandi/wc
f. Luar ruangan

3. Mengukur dan menghitung penggunaan energi dengan beban peralatan listrik lain seperti AC, kipas angin, komputer, printer, pemanas air, pompa air, viewer dan lain-lain dengan menggunakan multimeter, tang amper, Power Analyzer.

4. Mengukur luas ruangan

5. Mengukur tingkat pencahayaan dari masingmasing ruangan dengan menggunakan luxmeter

6. Membuat rekomendasi peningkatan efisiensi penggunaan energi listrik dengan peluang hemat energi (PHE) dalam rangka konservasi energi

\subsection{Analisis Data}

Kebutuhan energi setiap ruangan dihitung dengan menggunakan persamaan :

$$
W=V \times I \times \cos \theta \times t=P \times t
$$

Dengan

$\mathrm{W}=$ Energi (Watt jam)

$\mathrm{P}=$ Daya $($ Watt $)$

$\mathrm{T}=$ Waktu (jam)

Apabila pada ruangan tersebut terdapat beberapa peralatan listrik maka energi total adalah :

$$
W_{\text {Total }}=\sum_{n} W_{n}
$$

Untuk menentukan intensitas konsumsi listrik digunakan persamaan 6 berikut :

$$
I K E=\frac{\text { Total konsumsi Energi }}{\text { Luas Lantai total }}
$$

Menganalisa data keseluruhan guna membuat rekomendasi peningkatan efisiensi penggunaan energi listrik dengan peluang hemat energi (PHE) dalam rangka konservasi energi. 


\section{HASIL DAN PEMBAHASAN}

\section{Data dan Objek Pembahasan}

Data penggunaan energi listrik dan biaya rekening pembayarannya serta data dari pengukuran.

1. Pengumpulan data penggunaan energi listrik seperti pada tabel 4 .

Tabel 4. Penggunaan energi

\begin{tabular}{lccc} 
Bulan & $\begin{array}{c}\text { Daya } \\
(\mathrm{kW})\end{array}$ & $\begin{array}{c}\text { Energi } \\
(\mathrm{kWh})\end{array}$ & Biaya (Rp) \\
\hline ober 2018 & 1,35 & 972 & Rp. 927.800 \\
vember 2018 & 1,356 & 1009 & Rp. 961.100 \\
ember 2018 & 1,282 & 923 & Rp. 833.700 \\
ruari 2019 2019 & 0,832 & 619 & Rp. 610.100 \\
ret 2019 & 1,325 & 986 & Rp. 890.400 \\
\end{tabular}

2. Mengukur dan menghitung penggunaan energi dengan beban penerangan

Pengukuran dilakukan pada setiap ruangan, sehingga energi dapat dihitung dengan energi untuk penerangan pada ruang kepala sekolah adalah :

$$
W=P \times t=160 \times 200=32000 W h
$$

Energi untuk penerangan pada setiap ruang seperti pada tabel 5.

3. Mengukur dan menghitung penggunaan energi dengan beban peralatan listrik lain seperti AC, kipas angin, komputer, printer, pemanas air, pompa air, viewer dan lain-lain maksimum dengan menggunakan multimeter, tang amper, Power Analyzer.

4. Mengukur luas ruangan Pengukuran dilakukan pada setiap ruangan, sehingga energi dapat dihitung dengan energi untuk beban peralatan listrik pada ruang kepala sekolah beban printer adalah :

$$
W=P \times t=10 \times 12.5=125 W h
$$

Energi untuk beban peralatan listrik pada setiap ruang dapat dilihat pada tabel 6.

Tabel 5. Penggunaan energi dengan beban penerangan

\begin{tabular}{clccc}
\hline No & \multicolumn{1}{c}{ Ruangan } & $\begin{array}{c}\text { Daya } \\
\text { (Watt) }\end{array}$ & $\begin{array}{c}\text { Waktu } \\
\text { (jam) }\end{array}$ & $\begin{array}{c}\text { Energi } \\
\text { (Wh) }\end{array}$ \\
\hline 1 & Ruang Kepala Sekolah & 160 & 200 & 32000 \\
2 & Ruang Guru 1.1 & 80 & 200 & 16000 \\
3 & Ruang Guru 1.2 & 126 & 200 & 25200 \\
4 & Ruang kantor tata usaha & 120 & 200 & 24000 \\
5 & Ruang 1.3 & 160 & 100 & 16000 \\
6 & Ruang 1.4 & 160 & 50 & 8000 \\
7 & Ruang 1.5 & 160 & 200 & 32000 \\
8 & Ruang 1.6 & 160 & 100 & 16000 \\
9 & Ruang 1.7 & 92 & 125 & 11500 \\
10 & Ruang 1.8 & 92 & 200 & 18400 \\
11 & Ruang 2.1 & 160 & 100 & 16000 \\
12 & Ruang 2.2 & 160 & 100 & 16000 \\
13 & Ruang 2.3 & 160 & 200 & 32000 \\
14 & Ruang 2.4 & 160 & 200 & 32000 \\
15 & Ruang 2.5 & 56 & 200 & 11200 \\
16 & Ruang 2.6 & 56 & 200 & 11200 \\
17 & Kamar mandi/wc 1 & 23 & 75 & 1725 \\
18 & Kamar mandi/wc 2 & 23 & 75 & 1725 \\
19 & Kamar mandi/wc 3 & 23 & 75 & 1725 \\
20 & Kamar mandi/wc 4 & 23 & 75 & 1725 \\
21 & Luar ruangan & 138 & 200 & $\mathbf{3 5 2 . 0 0 0}$ \\
\hline & Total & & &
\end{tabular}


Tabel 6. Penggunaan energi dengan beban peralatan listrik

\begin{tabular}{|c|c|c|c|c|c|c|}
\hline No & Ruangan & Luas $\left(\mathrm{m}^{2}\right)$ & Jenis beban & $\begin{array}{c}\text { Daya } \\
\text { (Watt) }\end{array}$ & $\begin{array}{c}\text { Waktu } \\
\text { (jam) }\end{array}$ & $\begin{array}{c}\text { Energi } \\
(\mathrm{Wh})\end{array}$ \\
\hline \multirow{4}{*}{1} & \multirow{4}{*}{ Ruang Kepala Sekolah } & \multirow{4}{*}{36.04} & Printer & 10 & 12.5 & 125 \\
\hline & & & Laptop & 65 & 50 & 3250 \\
\hline & & & $\mathrm{AC}$ & 373 & 0 & 0 \\
\hline & & & Dispenser & 350 & 100 & 35000 \\
\hline \multirow{3}{*}{2} & \multirow{3}{*}{ Ruang Guru 1.1} & \multirow{3}{*}{8.84} & Printer & 10 & 25 & 250 \\
\hline & & & Laptop & 65 & 100 & 6500 \\
\hline & & & Kipas angin & 60 & 200 & 12000 \\
\hline \multirow{4}{*}{3} & \multirow{4}{*}{ Ruang Guru 1.2} & \multirow{4}{*}{35.36} & Printer & 10 & 25 & 250 \\
\hline & & & Laptop & 65 & 200 & 13000 \\
\hline & & & Kipas angin & 90 & 200 & 18000 \\
\hline & & & Dispenser & 350 & 100 & 35000 \\
\hline \multirow{4}{*}{4} & \multirow{4}{*}{$\begin{array}{l}\text { Ruang kantor tata } \\
\text { usaha }\end{array}$} & \multirow{4}{*}{17} & Printer & 10 & 25 & 250 \\
\hline & & & Laptop & 65 & 100 & 6500 \\
\hline & & & Kipas angin & 90 & 200 & 18000 \\
\hline & & & Dispenser & 350 & 100 & 35000 \\
\hline \multirow{2}{*}{5} & \multirow{2}{*}{ Ruang 1.3} & \multirow{2}{*}{53.04} & Kipas angin & 90 & 200 & 18000 \\
\hline & & & Dispenser & 350 & 0 & 0 \\
\hline \multirow{2}{*}{6} & \multirow{2}{*}{ Ruang 1.4} & \multirow{2}{*}{53.04} & Kipas angin & 90 & 200 & 18000 \\
\hline & & & Dispenser & 350 & 0 & 0 \\
\hline \multirow{2}{*}{7} & \multirow{2}{*}{ Ruang 1.5} & \multirow{2}{*}{53.04} & Kipas angin & 90 & 200 & 18000 \\
\hline & & & Dispenser & 350 & 100 & 35000 \\
\hline \multirow{2}{*}{8} & \multirow{2}{*}{ Ruang 1.6} & 5204 & Kipas angin & 90 & 200 & 18000 \\
\hline & & 53.04 & Dispenser & 350 & 100 & 35000 \\
\hline 0 & & & Kipas angin & 120 & 200 & 24000 \\
\hline 9 & Ruang $1 . /$ & 38.08 & Dispenser & 350 & 100 & 35000 \\
\hline 10 & & 5372 & Kipas angin & 90 & 200 & 18000 \\
\hline 10 & Ruang 1.8 & 53.12 & Dispenser & 350 & 100 & 35000 \\
\hline 11 & Ruang 21 & 5304 & Kipas angin & 90 & 200 & 18000 \\
\hline 11 & Kuang 2.1 & 53.04 & Dispenser & 350 & 100 & 35000 \\
\hline 12 & Ruang 2 ? & 5304 & Kipas angin & 90 & 200 & 18000 \\
\hline 12 & Kuang 2.2 & 53.04 & Dispenser & 350 & 100 & 35000 \\
\hline & & & Kipas angin & 90 & 200 & 18000 \\
\hline 13 & Ruang 2.3 & 49.64 & Dispenser & 350 & 100 & 35000 \\
\hline 14 & Ruang 24 & 5236 & Kipas angin & 90 & 200 & 18000 \\
\hline 14 & Ruang 2.4 & 52.36 & Dispenser & 350 & 100 & 35000 \\
\hline 15 & Ruang 25 & 476 & Kipas angin & 90 & 200 & 18000 \\
\hline 15 & Ruang $2 . J$ & $4 / .6$ & Dispenser & 350 & 100 & 35000 \\
\hline 16 & Ruang 26 & 4624 & Kipas angin & 90 & 200 & 18000 \\
\hline 10 & Kuang 2.0 & 40.24 & Dispenser & 350 & 100 & 35000 \\
\hline 17 & Kamar mandi/wc 1 & 10.89 & & & & \\
\hline 18 & Kamar mandi/wc 2 & 10.89 & Pomna air & 500 & 125 & 62500 \\
\hline 19 & Kamar mandi/wc 3 & 10.89 & Pompa air & 500 & 125 & \\
\hline 20 & Kamar mandi/wc 4 & 10.89 & & & & \\
\hline 21 & Luar Ruangan & 138 & & 0 & 0 & 0 \\
\hline & Total & 884.68 & & & & 798.875 \\
\hline
\end{tabular}


5. Mengukur tingkat pencahayaan dari masingmasing ruangan dengan menggunakan luxmeter seperti pada tabel 7 .

Tabel 7. Tingkat Pencahayaan

\begin{tabular}{clc}
\hline No & \multicolumn{1}{c}{ Nama Ruang } & $\begin{array}{c}\text { Tingkat } \\
\text { Pencahayaan } \\
\text { (Lux) }\end{array}$ \\
\hline 1 & Ruang Kepala Sekolah & 300 \\
2 & Ruang Guru 1.1 & 92 \\
3 & Ruang Guru 1.2 & 300 \\
4 & Ruang kantor tata usaha & 100 \\
5 & Ruang 1.3 & 300 \\
6 & Ruang 1.4 & 500 \\
7 & Ruang 1.5 & 104 \\
8 & Ruang 1.6 & 280 \\
9 & Ruang 1.7 & 160 \\
10 & Ruang 1.8 & 115 \\
11 & Ruang 2.1 & 280 \\
12 & Ruang 2.2 & 430 \\
13 & Ruang 2.3 & 160 \\
14 & Ruang 2.4 & 112 \\
15 & Ruang 2.5 & 173 \\
16 & Ruang 2.6 & 315 \\
\hline
\end{tabular}

\section{Analisis Hasil}

Total energi yang digunakan dari beban penerangan dan peralatan listrik adalah :

$$
\begin{aligned}
W_{\text {Total }} & =\sum_{n} W_{n} \\
& =352.000+798.875=1.150 .875 \mathrm{Wh} .
\end{aligned}
$$

Penggunaan energi yang pernah mendekati nilai ini adalah pada bulan November 2018 yaitu 1.009.000 Wh

Untuk menentukan intensitas konsumsi listrik setiap bulannya digunakan persamaan 6 dan perhitungan intensitas konsumsi listrik bulan Oktober adalah sebagai berikut :

$$
I K E=\frac{\text { Total } \text { konsumsi Energi }}{\text { Luas Lantai total }}=\frac{972 \mathrm{kWh}}{884.68 \mathrm{~m}^{2}}=1.1
$$

Sedangkan hasil untuk perhitungan intensitas konsumsi listrik setiap bulannya digunakan dapat dilihat pada tabel 8 berikut.

Penggunaan energi listrik disekolah ini dengan intensitas konsumsi listrik sangat effisien adalah bagus. Namun berdasarkan pengukuran tingkat pencahayaan di ruangan ternyata terdapat banyak ruangan yang tingkat pencahayaannya rendah dibawah batas tingkat pencahayaan minimum (standar nasional Indonesia 03-6197-tahun 2000) [7]. Pada SNI ini batas minimum tingkat pencahayaan ruang kelas adalah 250 lux, ruang kerja 350 lux dan kamar mandi 250 lux

Tabel 8. Intensitas Konsumsi Listrik

\begin{tabular}{clcccc}
\hline No & \multicolumn{1}{c}{ Bulan } & $\begin{array}{c}\text { Energi } \\
(\mathrm{kWh})\end{array}$ & $\begin{array}{c}\text { Luas bangunan } \\
\left(\mathrm{m}^{2}\right)\end{array}$ & $\begin{array}{c}\mathrm{IKE} \\
\left(\mathrm{kWh} / \mathrm{m}^{2}\right)\end{array}$ & Kriteria \\
\hline 1 & Oktober 2018 & 972 & & 1,099 & Sangat Effisien \\
2 & November 2018 & 1009 & & 1,14 & Sangat Effisien \\
3 & Desember 2018 & 923 & & 1,043 & Sangat Effisien \\
4 & Januari 2019 & 619 & 884,68 & 0,7 & Sangat Effisien \\
5 & Februari 2019 & 986 & & 1,115 & Sangat Effisien \\
6 & Maret 2019 & 848 & & 0,959 & Sangat Effisien \\
\hline
\end{tabular}

Diantara ruang yang tingkat pencahayaannya rendah dibawah batas tingkat pencahayaan minimum adalah Ruang Guru 1.1, Ruang kantor tata usaha, Ruang 1.5, Ruang 1.7, Ruang 1.8, Ruang 2.3, Ruang 2.4 dan Ruang 2.5. Diantara ruangan ini masih menggunakan lampu TL yang tidak terawat dan ada beberapa ruangan yang menggunakan lampu hemat energi dengan armature downlight sehingga pencahayaan kurang maksimal.

Sedangkan daya listrik maksimum per meter persegi tidak boleh melebihi nilai $15 \mathrm{Watt} / \mathrm{m}^{2}$ untuk ruang kerja dan ruang kelas. Diantar ruangan dengan daya yang melebihi adalah Ruang Guru 1.1 dan Ruang Kantor Tata Usaha. Untuk ruang kelas sudah memenuhi karena hanya menggunakan peralatan dispenser dan kipas angin.
Untuk AC yang berada diruang kepala sekolah yang belum dimanfaatkan dapat digunakan secara efektif karena secara keseluruhan penggunaan energi listrik sangat efisien. Untuk peningkatan efisiensi penggunaan energi listrik dengan peluang hemat energi (PHE) dalam rangka konservasi energi maka direkomendasikan sebagai berikut:

1. Merawat lampu serta armature lampu yaitu dengan cara membersihkannya agar sinar lampu maksimal.

2. Menyesuaikan penerangan ruangan dengan luas ruangan sehingga tingkat pencahayaan sesuai dengan penggunaan ruangan dan SNI

3. Mengganti Tuber lamp (lampu TL) dengan Lampu hemat energi. 
4. Merawat kipas angin yaitu dengan membersihkannya agar pendinginan ruangan dapat maksimal.

5. Menggunakan dispenser seefektif mungkin karena peralatan ini menggunakan daya tinggi.

6. AC yang beraga di ruang kepala sekolah dapat digunakan secara efektif.

\section{KESIMPULAN}

1. Tingkat effisiensi penggunaan energi listrik pada Gedung Madrasah Ibtidaiyah Muhammadiyah I Pekanbaru dengan menentukan nilai intensitas konsumsi Energi (IKE) rata rata selama 6 bulan adalah 1,009 (sangat effisien).

2. Namun berdasarkan pengukuran tingkat pencahayaan di ruangan ternyata terdapat banyak ruangan yang tingkat pencahayaannya rendah yaitu dibawah batas tingkat pencahayaan minimum (standar nasional Indonesia 03-6197tahun 2000). Diantara ruang yang tingkat pencahayaannya rendah dibawah batas tingkat pencahayaan minimum adalah Ruang Kepala Sekolah, Ruang Guru 1.1, Ruang Guru 1.2, Ruang kantor tata usaha, Ruang 1.5, Ruang 1.7, Ruang 1.8, Ruang 2.3, Ruang 2.4 dan Ruang 2.5.

\section{DAFTAR PUSTAKA}

[1] Joseph A.Edminister, 1994, Rangkaian Listrik seri buku schaum, Penerbit Erlangga

[2] Hayt, William H.JR, Jack E Kemmerly, 2005, Rangkaian Listrik II edisi keenam, Penerbit Erlangga

[3] James W. Nilsson, 2011, Electric Circuits Ninth Edition, Prentice Hall

[4] David E Johnson, Johnny R Johnson, 1992, Electric Circuit Analysis, Prentice Hall, Inc, New Jersey

[5] Jati Untoro, Herri G, Nining P, Audit Energi dan Analisis Penghematan Konsumsi Energi Pada Sistem Peralatan Listrik Di Gedung Pelayanan Unila, Electrician Jurnal Rekayasa Dan Teknologi Elektro, Vol. 8 no. 2 Mei 2014.

[6] SNI 0225:2011/Amd 1 2013, Persyaratan Umum Instalasi Listrik 2011 (PUIL 2011). Badan Standardisasi Nasional, Jakarta

[7] SNI 03-6196 2000, Prosedur audit energi pada bagunan, Badan Standardisasi Nasional, Jakarta

[8] SNI 03-6197 2000, Konservasi energi pada sistem pencahayaan, Badan Standardisasi Nasional, Jakarta.

[9] SNI 03-6390 2011, Konservasi energi sistem tata udara bangunan gedung, Badan Standardisasi Nasional, Jakarta. 